\title{
Dinâmica de populações de plantas daninhas na cana-de-açúcar em sistema de plantio direto e convencional ${ }^{1}$
}

\author{
Dynamics of populations of weed in the sugarcane in \\ system no-tillage and conventional one ${ }^{1}$
}

José Barbosa Duarte Júnior ${ }^{2 *}$; Fábio Cunha Coelho ${ }^{3}$; Silvério de Paiva Freitas ${ }^{4}$

\section{Resumo}

O objetivo deste trabalho foi avaliar a incidência e a dinâmica de populações de plantas daninhas na cultura da cana-de-açúcar em sistema de plantio direto (SPD) em comparação ao preparo convencional (PC), após tratamento com herbicidas. O delineamento experimental foi em blocos casualizados, com quatro repetições, num esquema fatorial 4x2. Os tratamentos foram: (I) - cana PC vegetação espontânea incorporada com adubação e (II) - idem I sem adubação; (III) - cana SPD sobre palhada feijão-deporco com adubação e (IV) - idem III sem adubação; (V) - cana SPD sobre palhada de mucuna preta com adubação e (VI) - idem V sem adubação e (VII) - cana SPD sobre palhada de crotalária juncea com adubação e (VIII) - idem VII sem adubação. As espécies Cyperus rotundus e Sorghum halepense apresentaram os maiores índices de valor de importância na área experimental. O SPD de cana-deaçúcar sobre feijão-de-porco apresentou o menor índice de similariedade na comunidade de plantas daninhas em relação à cana cultivada convencionalmente. A incidência de plantas daninhas na cana PC foi 531 e 525\% superior à cana SPD e contribuiu para a redução de $27 \%$ na produtividade.

Palavras-chave: Levantamento fitossociológico, Saccharum spp.

\begin{abstract}
The research aimed to evaluate the incidence and the populations dynamics in sugarcane crop in notillage system in comparison to the conventional one. The experimental design was completely random, using four replications, in a factorial 4x2 outline. The treatments were: (I) - sugarcane PC incorporated to spontaneous vegetation with manuring and (II) - the same procedure as in I without manuring; (III) - sugarcane SPD over jack bean (Canavalia ensiformis) with manuring and (IV) - the same procedure as in III without manuring; (V) - sugarcane SPD over velvet bean (Mucuna aterrima) with manuring and (VI) - the same procedure as in V without manuring and (VII) - sugarcane SPD over sunnhemp (Crotalaria juncea) with manuring and (VIII) - the same procedure as in VII without manuring. The species Cyperus rotundus and Sorghum halepense presented the highest rates of value of importance in the experimental area. Sugarcane SPD over jack bean presented the lowest similarity rate in the community of weed in relation to the sugarcane cultivated conventionally. The incidence of weed in the sugarcane PC was 531 and 525\% superior in to the sugarcane SPD, and contributed to the reduction of $27 \%$ in the yield.
\end{abstract}

Key words: Phyto-sociological survey, Saccharum spp.

1 Parte do trabalho da Tese de Doutorado do primeiro autor.

2 Eng ${ }^{\mathrm{o}} \mathrm{Agr}^{\mathrm{o}}$, D.Sc., Professor Adjunto, UNIOESTE/CCA/Agronomia. E-mail: bduarte7@yahoo.com.br.

3 Eng ${ }^{\circ}$ Agr $^{\circ}$, D.Sc., Professor Associado, UENF/CCTA/LFIT. E-mail: fcoelho@uenf.br.

${ }^{4}$ Eng $^{\text {o Agr }}{ }^{\circ}$, D.Sc., Professor Associado, UENF/CCTA/LFIT. E-mail: silverio@uenf.br.

Autor para correspondência. 


\section{Introdução}

A cultura da cana-de-açúcar ocupa grandes áreas plantadas no Brasil, sendo na safra de 2005 de seis milhões de hectares, que produziu 440 milhões de toneladas de colmos com produtividade média de 74 ton $\mathrm{ha}^{-1}$, que pode ser considerada baixa em relação ao potencial produtivo da cultura (COMPANHIA NACIONAL DE ABASTECIMENTO, 2005). Vários fatores são responsáveis pela redução na produtividade da cana, destacando-se a interferência das plantas daninhas, somatória da competição imposta aos fatores limitantes do meio (água, luz e nutrientes) com a hospedagem de pragas e doenças, a liberação de substâncias alelopáticas e as dificuldades na colheita (PITELLI, 1985).

A presença de plantas daninhas pode acarretar grandes prejuízos durante o ciclo produtivo da cana-de-açúcar. Todavia, a dinâmica populacional de plantas daninhas varia em função de diferentes aspectos: da época do ano, da fase da cultura, se cana-planta ou soca; das condições edafoclimáticas (OLIVEIRA, 2005); do manejo de solo, plantio direto ou convencional (JAKELAITIS et al., 2003; LACERDA; VICTORIA FILHO, 2004), dos tipos de cobertura do solo, sejam adubos verdes e/ou da própria palha da cana (AZANIA et al., 2002; EVANGELISTA JUNIOR et al., 2004).

Assim, devido a variabilidade de fatores que interferem sobre as plantas daninhas Deuber (1997) recomenda fazer levantamento fitossociológico, com objetivo de conhecer qualitativa e quantitativamente as espécies que ocorrem em cada condição, proporcionando manejo mais racional. A fitossociologia possibilita o estudo comparativo das populações de plantas daninhas num determinado momento (PITELLI, 2000). Segundo Pitelli (2000) esta ciência possibilita o levantamento das plantas daninhas presentes, identificando as espécies presentes na área, aquelas que têm maior importância, levando-se em consideração os parâmetros de freqüência, densidade e dominância. Posteriormente, podem-se tomar decisões quanto ao melhor manejo a ser adotado. Nesse caso, Victória Filho (2003) sugere, com base na literatura recente, para o manejo de plantas daninhas o método integrado e sustentável.

O sistema de plantio direto se apresenta como uma ferramenta importante neste contexto, pois pode ser entendido pelo seu próprio conceito, uma vez que assume a visão integrada de um sistema, envolvendo a combinação de práticas culturais ou biológicas, tais como: o uso de produtos químicos ou práticas mecânicas no manejo de culturas destinadas à adubação verde, para a formação de coberturas do solo, através da manutenção dos resíduos culturais na superfície do solo; a combinação de espécies com exigência nutricional, produção de fitomassa e sistema radicular diferenciados, visando a constituir uma rotação de culturas; a adoção de métodos integrados de controle de plantas daninhas, através da cobertura dos solos, herbicidas e o não revolvimento do solo, exceto no sulco de semeadura (SÁ, 1998). O sistema de plantio direto apresenta maior eficiência no controle cultural das plantas daninhas que os sistemas de cultivo mínimo e preparo convencional, reduzindo o número total de indivíduos e a comunidade infestante (PEREIRA; VELINI, 2003).

A colheita da cana-de-açúcar no sistema de plantio direto é crua, ou seja, sem queima prévia, minimizando os problemas que a colheita tradicional com queima causa ao homem e ao meio ambiente. Assim, os efeitos alelopáticos e supressivos proporcionados por espécies de adubos verdes e seus resíduos remanescentes, prática intrínseca do plantio direto, sobre plantas daninhas auxiliam o seu manejo, juntamente com os efeitos respectivos da própria palhada da cana que se acumula na superfície do solo (SEVERINO; CHRISTOFFOLETI, 2001; AZANIA et al., 2002; ERASMO et al., 2004).

Nesse sentido, este trabalho objetivou avaliar a incidência e a dinâmica de populações de plantas daninhas na cultura da cana-de-açúcar em sistema de plantio direto em comparação ao convencional. 


\section{Material e métodos}

O experimento de campo foi conduzido na Fazenda Abadia em Campos dos Goytacazes (situado a $21^{\circ} 44^{\prime} 47^{\prime \prime}$ de latitude Sul e $41^{\circ} 18$ '24" de longitude Oeste com altitude de 12 metros), no Estado do Rio de Janeiro, durante o período de 30 de março de 2004 a 01 julho de 2005.

A análise química do solo, anterior à instalação do experimento, evidenciou valores de $\mathrm{pH}\left(\mathrm{H}_{2} \mathrm{O}\right)=$ 5,5; $\mathrm{S}_{-} \mathrm{SO}_{4}=17,8\left(\mathrm{mg} \mathrm{dm}^{-3}\right) ; \mathrm{P}=41,8\left(\mathrm{mg} \mathrm{dm}^{-3}\right)$; $\mathrm{K}^{+}=0,34\left(\mathrm{cmol}_{\mathrm{c}} \mathrm{dm}^{-3}\right) ; \mathrm{Ca}^{++}=5,03\left(\mathrm{cmol}_{\mathrm{c}} \mathrm{dm}^{-3}\right)$; $\mathrm{Mg}^{++}=2,47\left(\mathrm{cmol}_{\mathrm{c}} \mathrm{dm}^{-3}\right) ; \mathrm{Al}^{+++}=0,22\left(\mathrm{cmol}_{\mathrm{c}} \mathrm{dm}^{-3}\right)$; $\mathrm{H}^{+}+\mathrm{Al}=4,31\left(\mathrm{cmol}_{\mathrm{c}} \mathrm{dm}^{-3}\right) ; \mathrm{Na}^{+}=0,22\left(\mathrm{cmol}_{\mathrm{c}}\right.$ $\left.\mathrm{dm}^{-3}\right) ; \mathrm{C}=19,4\left(\mathrm{~g} \mathrm{dm}^{-3}\right)$; M.O. $=33,4\left(\mathrm{~g} \mathrm{dm}^{-3}\right) ; \mathrm{Fe}=$ 127,0 (mg dm$\left.{ }^{-3}\right) ; \mathrm{Cu}=3,2\left(\mathrm{mg} \mathrm{dm}^{-3}\right) ; \mathrm{Zn}=3,9(\mathrm{mg}$ $\left.\mathrm{dm}^{-3}\right) ; \mathrm{Mn}=14,7\left(\mathrm{mg} \mathrm{dm}^{-3}\right)$ e $\mathrm{B}=0,4\left(\mathrm{mg} \mathrm{dm}^{-3}\right)$. A calagem foi realizada em novembro de 2003, com quatro meses de antecedência do plantio da cana, aplicando-se calcário calcítico com PRNT de 80\%, na dose de 0,75 toneladas por hectare. Foi aplicado como melhorador da fertilidade do solo o gesso agrícola, tomando-se de base $30 \%$ da recomendação de calagem, o que resultou na dose de 0,23 toneladas por hectare.

Posteriormente, foram cultivados os adubos verdes crotalária (Crotalaria juncea), feijão de porco (Canavalia ensifomis) e mucuna preta (Mucuna aterrima), objetivando a cobertura e proteção do solo, a acumulação de nutrientes e a formação de palhada para a implantação do sistema de plantio direto de cana-de-açúcar.

O delineamento experimental foi em blocos casualizados, com quatro repetições, em esquema fatorial $4 \times 2$. Os tratamentos foram: (I) - cana PC vegetação espontânea incorporada com adubação e (II) - idem I sem adubação; (III) - cana SPD sobre feijão de porco com adubação e (IV) - idem III sem adubação; (V) - cana SPD sobre mucuna com adubação e (VI) - idem V sem adubação e (VII) cana SPD sobre crotalária com adubação e (VIII) - idem VII sem adubação.
A parcela ou unidade experimental de $11 \mathrm{~m}$ de largura e $11 \mathrm{~m}$ de comprimento teve 8 linhas espaçadas de 1,3 m para a cana-de-açúcar, totalizando $121 \mathrm{~m}^{2}$. A área total do experimento foi de $3.872 \mathrm{~m}^{2}$. Os blocos foram dispostos seguindo transversalmente ao gradiente de argila do terreno determinado pela análise textural do solo, com uma faixa de $2 \mathrm{~m}$ separando os blocos. Foi utilizada a cultivar SP80-1842, na condição de cana-planta de ano-e-meio.

Nas parcelas da cana convencional, preparou-se o solo com uma aração média e duas operações de gradagem, utilizando-seum trator da marca Ford 6630 acoplado ao arado de discos e a grade niveladora. Em 30 de março de 2004, fez-se a sulcagem com auxílio de trator da marca Ford 6630, acoplado a um sulcador de duas linhas e, posteriormente fezse o plantio manual da cana com e sem adubação na base, com sulcos de $0,4 \mathrm{~m}$ profundidade, para o sistema de plantio direto e convencional. Nos tratamentos com adubação foi aplicado 444 e 133 $\mathrm{kg} \mathrm{ha}^{-1}$ de superfosfato simples e cloreto de potássio, respectivamente, com expectativa de 150 ton $\mathrm{ha}^{-1}$, utilizando-se de base o Boletin 100 do IAC (RAIJ et al., 1996). Foi considerada emergência da cana-deaçúcar, a época em que aproximadamente $50 \%$ dos brotos emergiram.

Para manejo das plantas daninhas na canaplanta em todos os tratamentos igualmente aos 15 dias após o plantio (DAP), foi realizada a aplicação de herbicidas pré e pós-emergentes, diuron + hexazinona na dose de $2,0 \mathrm{~kg} \mathrm{ha}^{-1}$ do produto comercial e metano arseniato ácido monossódico (MSMA) na dose de 2,4 $\mathrm{kg} \mathrm{ha}^{-1}$ do produto comercial, além do espalhante adesivo aquil fenol poliglicoléter na concentração de $2 \%$ do volume da calda, sendo de $200 \mathrm{~L} \mathrm{ha}^{-1}$ o volume de calda. A aplicação foi realizada no período da manhã das 06:18 às 07:03 horas, para evitar a deriva causada pelo vento e perdas por evaporação devido a altas temperaturas. Não houve incidência de pragas e doenças na cultura em nível de causar danos econômicos ou experimentais. Irrigou-se somente 
quando extremamente necessário, utilizando o sistema de aspersão para irrigação.

Para quantificação das plantas daninhas foi utilizado, como unidade amostral, um quadro $(0,25$ $\mathrm{m}^{2}$ ), lançando aleatoriamente dentro da área de estudo que abrangia $121 \mathrm{~m}^{2}$. Foram efetuadas 4 amostras por tratamento, como são oito tratamentos totalizaramse 32 amostras em toda área experimental, no período de outono-inverno. As espécies presentes em cada quadro foram cortadas rente ao solo, acondicionadas em sacos de papel e levadas para o laboratório de Fitotecnia da Universidade Estadual do Norte Fluminense Darcy Ribeiro, onde foram identificadas por meio de literatura especializada, comparações com material de herbário e, quando necessário, foram enviadas a especialistas. Após a identificação as plantas foram levadas para secagem em estufa à temperatura de $70^{\circ} \mathrm{C}$ por 72 horas para obtenção da biomassa seca.

Avaliou-se a freqüência absoluta, a freqüência relativa, a densidade absoluta, a densidade relativa, a dominância absoluta, a dominância relativa e o índice de valor de importância de acordo com Curtis e McIntosh (1950) e Mueller-Dombois e Ellenberg (1974):

Densidade absoluta de Indivíduos

$$
D a=\frac{n}{a}
$$

onde:

$D a=$ Densidade absoluta

$n=$ número total de indivíduos de uma espécie de planta daninha por unidade de área

$a=$ área $\left(\mathrm{m}^{2}\right)$

Densidade Relativa onde:

$D r=$ densidade relativa

$n=$ número total de indivíduos de uma espécie de planta daninha por unidade de área

$a=$ área $\left(\mathrm{m}^{2}\right)$

$N$ = número total de indivíduos amostrados de todas as espécies do levantamento

\section{Freqüencia Absoluta}

$F a=\frac{\text { número de amostras com ocorrência de espécie }}{\text { número total de amostras }} \times 100$

onde:

$F a=$ freqüência absoluta

\section{Freqüencia Relativa}

$$
F r=\frac{F a}{\sum_{F a}} \times 100
$$

onde:

$F r=$ freqüência relativa

$F a=$ freqüência absoluta

Dominância Absoluta

$$
D \circ A=\frac{\Sigma g}{a}
$$

onde:

$D \circ A=$ dominância absoluta

$g=$ matéria seca da espécie $(\mathrm{g})$

$a=$ Área $\left(\mathrm{m}^{2}\right)$

\section{Dominância Relativa}

$$
D o R=\frac{g / a}{G / a} \times 100
$$

$$
D r=\frac{n / a}{N / a} \times 100
$$


onde:

$D o R=$ dominância relativa

$g=$ matéria seca da espécie $(\mathrm{g})$

$a=$ Área $\left(\mathrm{m}^{2}\right)$

$G=$ matéria seca total da comunidade infestante

Índice de Valor de Importância

$$
I V I=D r+D o R+F r
$$

onde:

IVI = índice de valor de importância

Dr $=$ densidade relativa

$\mathbf{D o R}=$ dominância relativa

$\mathbf{F r}=$ freqüência relativa

Para avaliação da similaridade entre as populações botânicas na área experimental, cana-planta adubada x cana-planta não adubada, vegetação espontânea (VE) cana-planta PC x feijão de porco cana-planta SPD, VE cana-planta PC x mucuna cana-planta SPD, VE cana-planta PC x crotalária cana-planta SPD, foi utilizado o IS - Índice de Similaridade de Sorensen (1972).

\section{Índice de Similaridade}

$$
I S=(2 a / b+c) \times 100
$$

onde:

IS = índice de similaridade

$\mathbf{a}=$ número de espécies comuns às duas áreas

$\mathbf{b} \mathbf{e} \mathbf{c}=$ número total de espécies nas duas áreas comparadas

O IS varia de 0 a 100, sendo máximo quando todas as espécies são comuns às duas áreas e mínimo quando não existem espécies em comum.
Os resultados de número de plantas e matéria seca da espécie predominante, número total de plantas folhas largas, folhas estreitas e todas plantas daninhas, açúcares teoricamente recuperáveis e produtividade de colmos da cana-de-açúcar, foram analisados estatisticamente. Fez-se a análise de variância aplicando-se o Teste $\mathrm{F}$ em nível de 5\% de probabilidade, e as médias dentro de cada sistema de manejo foram comparadas pelo teste de Tukey em nível de 5\% de probabilidade (FERREIRA, 2000; RIBEIRO JÚNIOR, 2001).

\section{Resultados e discussão}

As observações realizadas 'in loco', nos tratamentos aplicados em nível de campo no experimento, caracterizaram-se pela estreita diversidade da flora infestante. Foram identificadas quatro espécies de plantas daninhas incidindo na cultura da cana-de-açúcar aos 69 dias após a emergência (DAE), no período de outono-inverno, distribuídas em quatro gêneros e três famílias, como pode ser observado na Tabela 1. A família mais representativa de todo o levantamento, no que se refere a número de espécies, foi a Poaceae, com duas espécies, seguida das duas outras famílias presentes na área, as quais apresentaram apenas uma espécie cada. A distribuição das plantas daninhas encontradas no levantamento fitossociológico, de acordo com a família, a espécie e o nome comum, também foi encontrada no trabalho de levantamento fitossociológico de plantas daninhas desenvolvido na mesma região em estudo por Oliveira (2005). Entretanto, o estudo de Oliveira (2005) foi mais aprofundado, pois incluiu, além de diferentes épocas do ano, também ambientes distintos, portanto, encontrando, desta forma, número consideravelmente superior de famílias e respectivas espécies. 
Tabela 1. Distribuição das plantas daninhas por família e espécie obtidas através de levantamento fitossocilógico em experimento de cana-planta aos 69 DAE em sistema de plantio direto e convencional no período de outono-inverno na Fazenda Abadia em Campos dos Goytacazes - RJ

\begin{tabular}{ccc}
\hline Família & Espécie & Nome comum \\
\hline Asteraceae & Emilia sonchifolia & falsa serralha \\
Cyperaceae & Cyperus rotundus & tiririca \\
Poaceae & Sorghum halepense & capim-massambará \\
& Brachiaria mutica & capim-angola \\
\hline
\end{tabular}

A espécie Cyperus rotundus, conhecida vulgarmente por tiririca, apresentou o maior índice de valor de importância $(203,21)$ em relação à comunidade infestante (Figura 1). Este resultado corrobora com os deOliveira (2005), o qual encontrou índice de valor de importância semelhante para a mesma espécie da planta daninha. A tiririca apresenta ótima adaptabilidade na região Norte Fluminense, pois é uma planta $\mathrm{C}_{4}$ de fixação de carbono, o que lhe confere altas taxas fotossintéticas em condições de altas temperaturas e alta luminosidade (TAIZ; ZEIGER, 2004) e, nesta região, a temperatura e a radiação solar média anual, respectivamente, é de $24^{\circ} \mathrm{C}$ e $199 \mathrm{~W} \mathrm{~m}^{-2}$. O índice de valor de importância (IVI), representado pelo somatório da densidade relativa, da freqüência relativa e da dominância relativa, indica qual espécie tem maior influência dentro de uma comunidade e, nesse caso, a densidade relativa $(71,28 \%)$ e a freqüência relativa $(68,75 \%)$ foram os que mais contribuíram para o maior IVI da tiririca. Oliveira (2005) também constatou maior IVI da tiririca na cana-soca e do capim-camalote (Rottboellia exaltata) na cana-planta em Campos dos Goytacazes - RJ.

É importante ressaltar que os parâmetros utilizados no levantamento fitossociológico levam em consideração o número de manifestações epígeas e o peso da fitomassa seca da parte aérea, não considerando o sistema radicular. Assim, a tiririca pode ter valor de importância ainda maior dentro da comunidade infestante, uma vez que, em condições favoráveis, a Cyperus rotundus pode produzir até 8.700 tubérculos por metro quadrado, os quais liberam substâncias alelopáticas no solo, afetanto negativamente o desenvolvimento das plantas circunvizinhas, dentre elas a cultura da cana-de-açúcar, que sofre inibição na brotação de gemas e no perfilhamento da cana, o que resulta em estandes desuniformes em áreas com alta incidência de tiririca (DURIGAN, 1991; KISSMANN, 1997).

Outra espécie que merece destaque é o campimmassanbará (Sorghum halepense) que também tem causado muitos prejuízos à lavoura canavieira e, neste levantamento, apresentou índice de valor de importância $(77,58)$, conforme Figura 1. Pode-se verificar que, das três espécies encontradas, duas são monocotiledôneas e uma é dicotiledônea. Tal ocorrência pode ser justificada pelo manejo adotado na cultura, em particular o uso de herbicidas que, enquanto seletivos à cana-de-açúcar (monocotiledôneas), podem ser seletivos às demais monocotiledôneas (plantas daninhas), reduzindo, assim, o controle das espécies da mesma família botânica, além de se adaptarem perfeitamente às mesmas condições edafoclimáticas. 


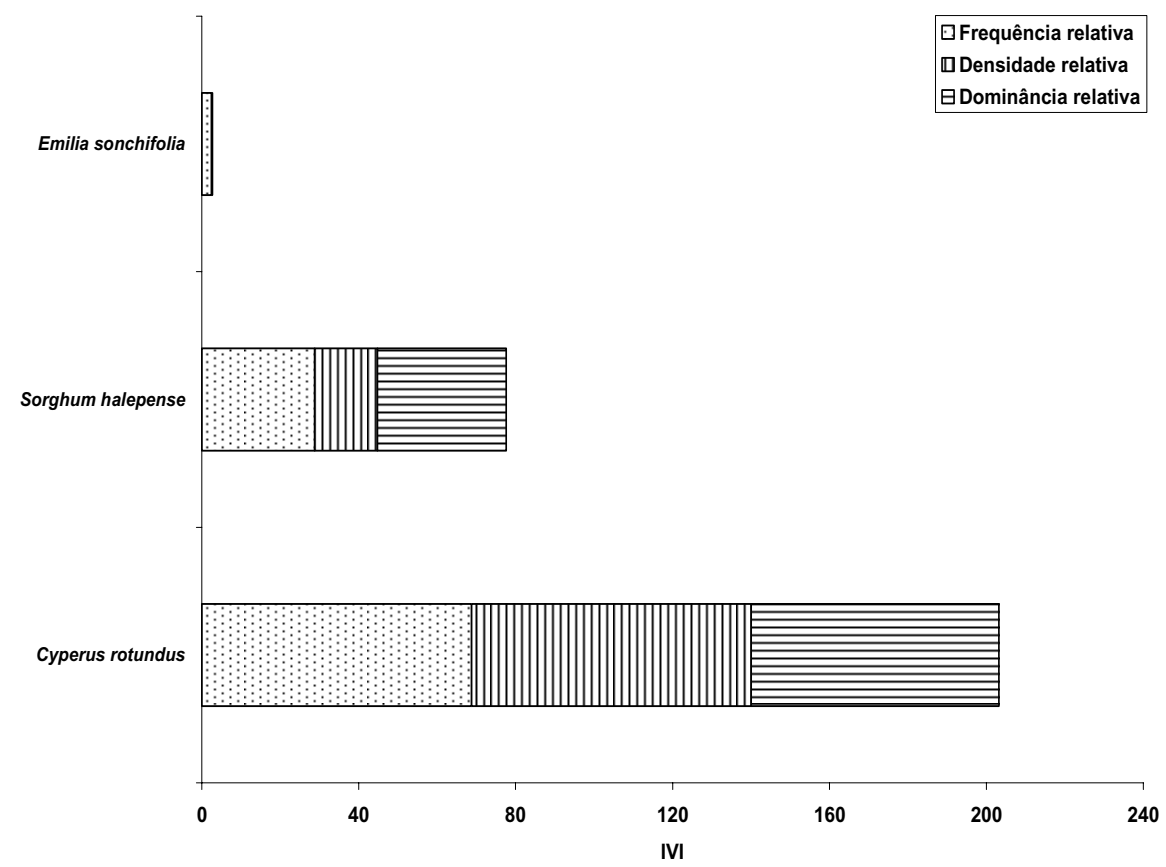

Figura 1. Índice de Valor de Importância (IVI) geral das principais espécies infestantes da área experimental com cana-planta aos 69 DAE em sistema de plantio direto (SPD) e convencional (PC) no outono-inverno na Fazenda Abadia em Campos dos Goytacazes - RJ

No preparo convencional, o campim-massambará e a falsa serralha nem apresentam IVI. Avaliando os resultados obtidos de cana-planta com adubo (Figura 2A) e sem adubo (Figura 2B), verifica-se, independente do manejo da fertilidade do solo, novamente o maior índice de valor de importância da Cyperus rotundus $(300,00)$ e $(290,49)$, respectivamente. Coelho et al. (2001) sugeriram que a adubação com $\mathrm{N}$ possibilitou ao feijão comum competir melhor com as plantas daninhas, a ponto de diminuir sua incidência. Entretanto, não se observou o mesmo nestas condições, possivelmente por serem culturas e adubações diferentes, pois foram utilizadas apenas fontes de fósforo e potássio. Todavia, o alto IVI pode ser justificado pelo emprego do PC do solo, o qual proporciona condições favoráveis para a propagação e maior incidência de espécies de plantas daninhas na cultura canavieira (PEREIRA; VELINI, 2003). A tiririca se reproduz quase que exclusivamente por tubérculos (LORENZI, 2000), dessa maneira, o PC não só multiplica cortando os tubérculos, como também espalha pela área cultivada, contribuindo, efetivamente, para maior incidência desta planta daninha.
Vale ressaltar que a espécie de $C$. rotundus se apresenta com elevada densidade relativa, isto se deve ao fato de que em cana-planta, o preparo do solo para o plantio propicia maior germinação e desenvolvimento desta espécie. Comprovadamente, este fenômeno foi observado e relatado por vários pesquisadores (FERREIRA et al., 2000; FREITAS; COELHO; PESSANHA, 2001), segundo os quais o emprego do preparo convencional favorece a propagação pela divisão da seqüência de tubérculos e pela eliminação da dominância apical exercida pelo tubérculo distal.

Levantamento fitossociológico, realizado no período de outono-inverno e primavera-verão por Oliveira (2005), indicou a Bidens pilosa, Cynodon dactylon e Panicum maximum como espécies de maior importância no outono-inverno, enquanto Pennisetum atropurpureu, Brachiaria mutica e Paspalum paniculatum são de maior importância na primavera-verão. E, ainda, que a $C$. rotundus aparece em primeiro lugar em IVI no período de primavera-verão, mas ocupou a segunda colocação em importância no outono-inverno, sendo superada nestas últimas estações pela Rottboellia exaltata. 


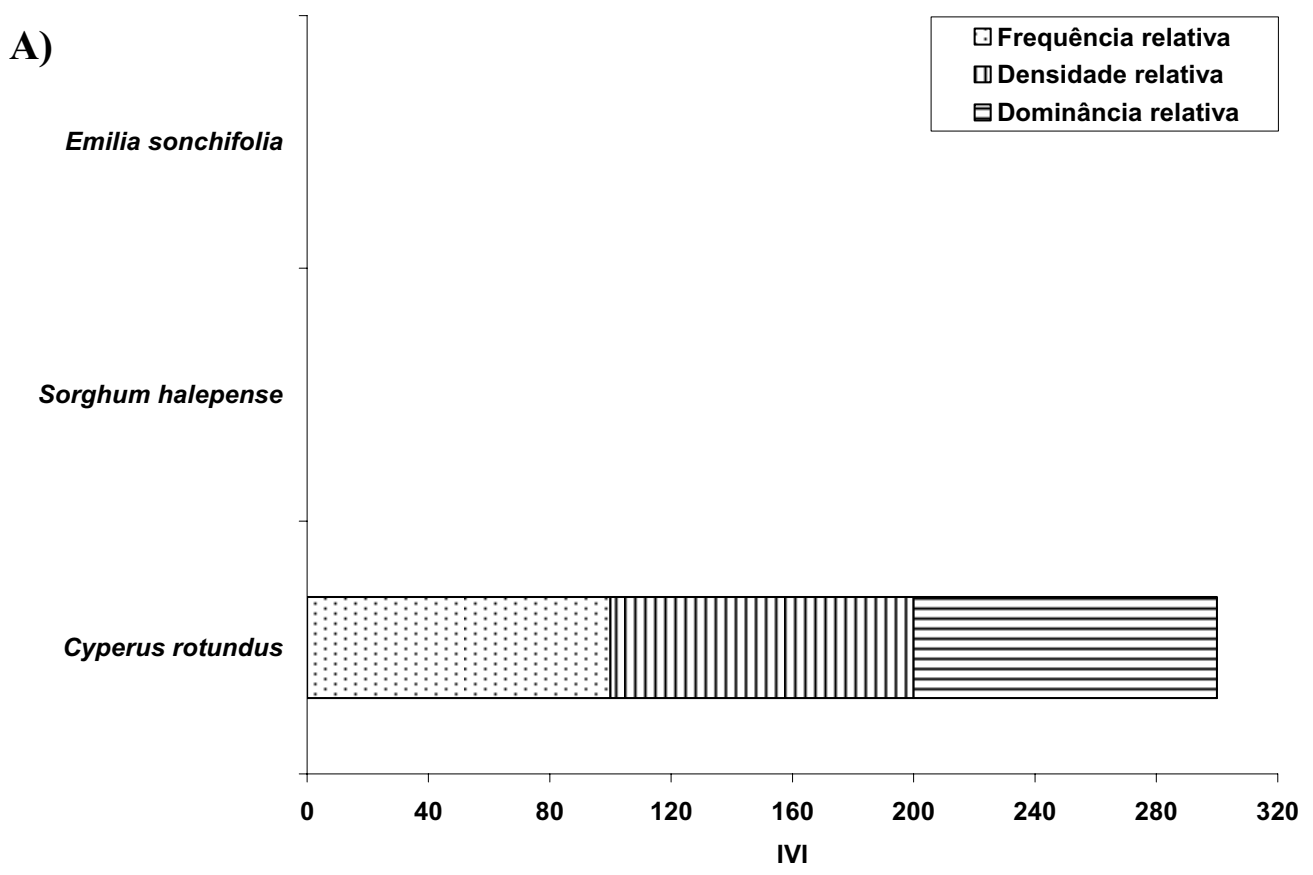

B)

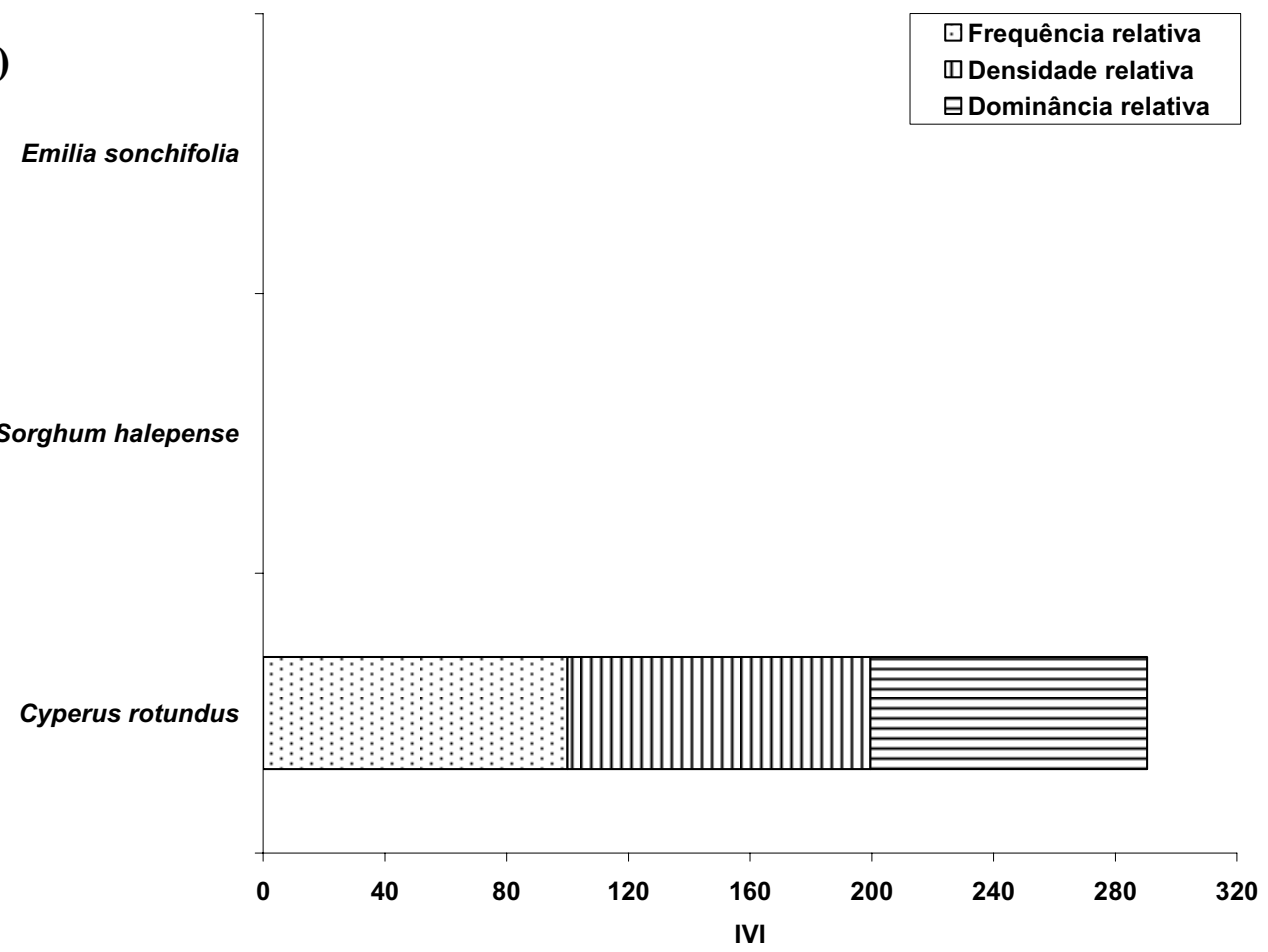

Figura 2. Índice de Valor de Importância (IVI) das principais espécies de plantas daninhas amostradas em área experimental de cana-planta em sistema de plantio convencional em Campos dos Goytacazes - RJ, A) cana PC com adubo; B) cana PC sem adubo 

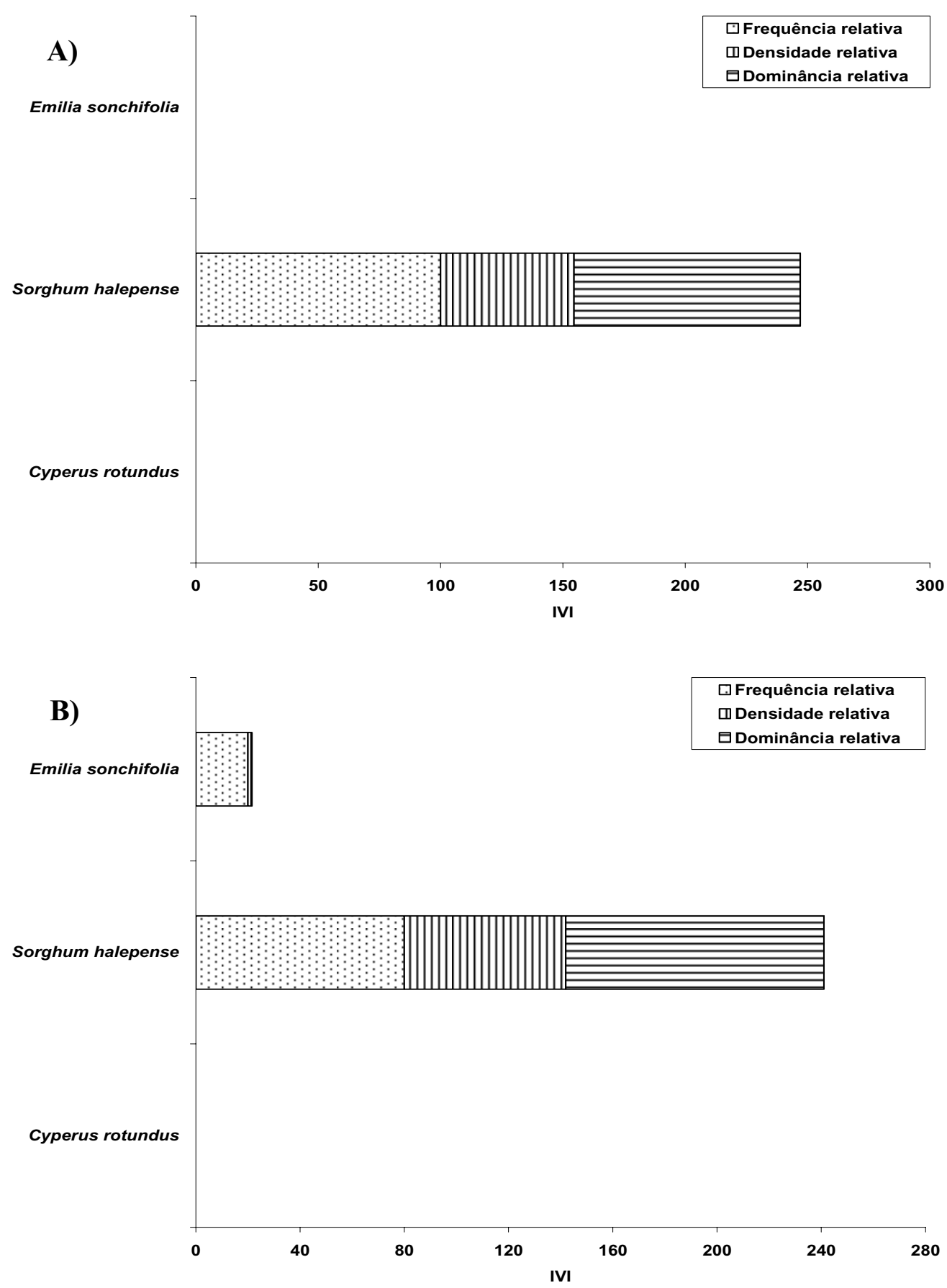

Figura 3. Índice de Valor de Importância (IVI) das principais espécies de plantas daninhas amostradas em área experimental de cana-planta em sistema de plantio direto em Campos dos

Figura 3. Índice de Valor de Importância (IVI) das principais espécies de plantas daninhas amostradas em área experimental de cana-planta em sistema de plantio direto em Campos dos Goytacazes - RJ, A) cana SPD sobre feijãode-porco com adubo; B) cana SPD sobre feijão-de-porco sem adubo 
$\mathrm{Na}$ cana cultivada em sistema de plantio direto sobre o feijão-de-porco, pode-se observar que o maior índice de valor de importância foi apresetado pelo Sorghum halepense, para cana com adubo $(247,02)$ e cana sem adubo $(241,04)$, quando comparado a Emilia sonchifolia $(21,52)$, somente na cana sem adubo, e a Cyperus rotundus que apresentou zero IVI, conforme a Figura 3A e 3B. Estes resultados evidenciam os possíveis efeitos alelopáticos proporcionados pelo feijãode-porco sobre as plantas daninhas (ERASMO et al., 2004), mas, principalmente, sobre a tiririca. A Emilia sonchifolia foi a única espécie de folha larga encontrada no levantamento, mas sua incidência foi de baixo índice de valor de importância, e sendo de fácil controle quando do manejo de plantas daninhas na cultura canavieira.

A espécie Sorghum halepense, conhecida vugarmente por capim-massambará, se apresentou em primeiro lugar em termos de IVI em relação à comunidade infestante da área de cana em SPD (Figura 3A e 3B). O capim-massambará apresenta o ciclo $\mathrm{C}_{4}$ de fixação de carbono, o que lhe confere altas taxas fotossintéticas em condições de altas temperaturas e alta luminosidade (TAIZ; ZEIGER, 2004). Portanto, como já foi mencionado anteriormente, a região Norte Fluminense oferece todas as condições climáticas requeridas para $\mathrm{o}$ máximo desenvolvimento de plantas $\mathrm{C}_{4}$. Assim, o capim-massambará, neste local, pode ser considerado a espécie daninha com maior potencial para causar prejuízos à cultura da cana-planta em SPD sobre feijão-de-porco. No entanto, a tendência a médio e longo prazo com o emprego do SPD e o acúmulo de palha na superfície do solo é de reduzir a incidência de plantas daninhas quando comparada ao preparo convencional (DURIGAN; MARTINI; LEITE, 2002; PEREIRA; VELINI, 2003).

Para a cana-de-açúcar cultivada em SPD sobre mucuna preta, conforme mostra as Figuras 4A e 4B, com e sem aplicação de adubo a Cyperus rotundus se destacou com os maiores índices de valor de importância 300,00, para cana adubada e 283,51 na cana não adubada. Esta espécie daninha foi encotrada e quantificada no levantamento fitossociológico vegetando, ainda que bem suprimida, sob a cobertura da mucuna. Por outro lado, pesquisas têm indicado a mucuna como destaque em efeitos supressivos sobre as plantas daninhas (ERASMO et al., 2004). O potencial da mucuna é reconhecido na literatura devido à sua agressividade como barreira física e ao seu efeito alelopático, que inibe o crescimento de plantas espontâneas, prevalecendo desde o início do ciclo até o seu final (MEDEIROS, 1989). Entretanto, timidamente a tiririca se apresentou mesmo em área de SPD de cana-de-açúcar sobre mucuna, possivelmente por estar no início do SPD e ainda com pouco volume de palha na superfície do solo.

O SPD de cana-de-açúcar favorece o acúmulo de palha da própria cultura, pois a cana é colhida crua. Assim, além de eficiente no sequestro de carbono atmosférico, atenuando o efeito estufa, resultados de pesquisa têm indicado efeitos da palhada da própria cana na incidência e controle de plantas daninhas na cultura até os 90 dias após o início da brotação da cana e aumentando o rendimento de colmos e de açúcar por área (FIGUEIREDO et al., 2002), a presença de 20 ton ha ${ }^{-1}$ de palha reduziu em 82,65 , $62,70,60$ e $88 \%$ o número de plantas de Ipomea quamoclit, I. purpurea, I. grandifolia, I. hederifolia, I. nil e Merremia cissoides, respectivamente, quando comparadas à ausência de palha (AZANIA et al., 2002). Dessa maneira, os resultados obtidos apresentando a presença de plantas daninhas podem ser justificados pelo fato do SPD de cana se encontrar na fase de implantação. Portanto, como não foi realizada, até este momento, nenhuma colheita da cana, não se apresentaram os comprovados efeitos da palha da cana, mas simplesmente os possíveis efeitos supressivos e alelopáticos dos adubos verdes utilizados para cobertura do solo. 

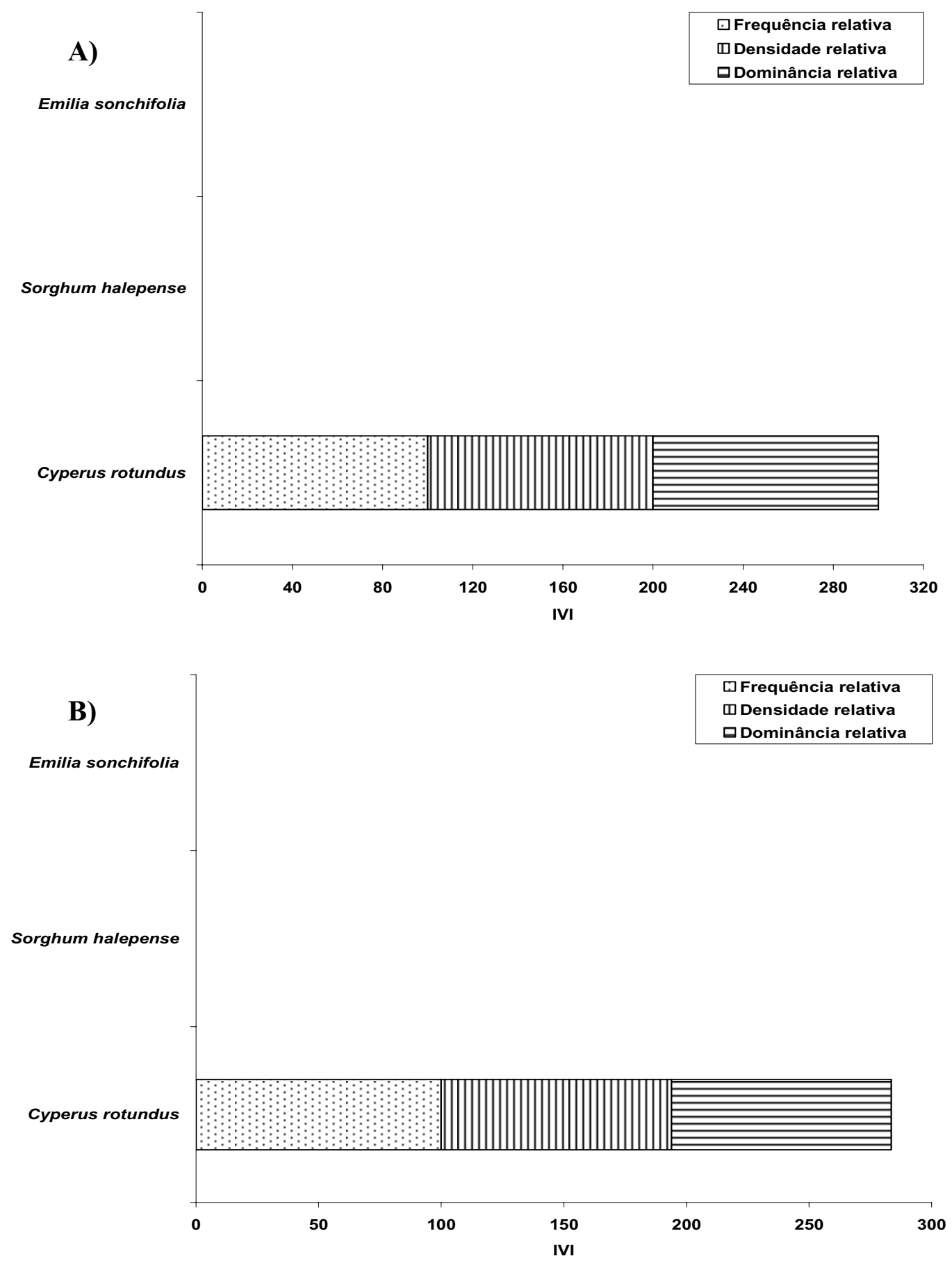

Figura 4. Índice de Valor de Importância (IVI) das principais espécies de plantas daninhas amostradas em área experimental de cana-planta em sistema de plantio direto em Campos dos Goytacazes - RJ, A) cana SPD sobre mucuna preta com adubo; B) cana SPD sobre mucuna preta sem adubo 
Avaliando o controle químico da tiririca com e sem cobertura do solo com a palha remanescente da colheita mecânica da cana-de-açúcar, Durigan, Martini e Leite (2002) constataram que a cobertura morta com palha de cana reduziu a infestação de tiririca, mas prejudicou a ação dos herbicidas Sulfentrazone (1,4 L ha-1) e Imazapic $\left(0,15 \mathrm{~kg} \mathrm{ha}^{-1}\right)$, sendo que o mesmo não ocorreu para os aplicados em pós-emergência.

Assim como ocorreu no trabalho realizado por Durigan, Martini e Leite (2002), pode ter ocorrido neste trabalho, ou seja, a palhada dos adubos verdes, possivelmente, exerceu o efeito guarda-chuva sobre algumas poucas plantas daninhas presentes na área experimental, dificultando o acerto do alvo (plantas daninhas), inclusive a tiririca, por ocasião da aplicação dos herbicidas.

A Cyperus rotundus se apresentou em primeiro lugar quanto ao índice de valor de importância 260,42 para cana adubada e 191,66 na área de cana sem adubo em SPD sobre crotalária, como pode ser visualizado nas Figuras 5A e 5B. O que mais contribuiu para que esta espécie obtivesse o maior IVI na cana SPD sobre crotalária com adubo foi a dominância relativa $(94,72 \%)$ e a densidade relativa (90,70\%), caracterizando o benefício promovido pela adubação, que foi explorada competitivamente com a cana pela tiririca, e evidenciado pelo elevado número de plantas por área e acúmulo de matéria seca. Já a área de cana SPD sobre crotalária sem adubo o maior IVI apresentado pela $C$. rotundus foi proporcionado, principalmente, pela densidade relativa $(86,05 \%)$, seguida de freqüência relativa $(75,00 \%)$.

O Sorghum halepense também deve ser destacado, uma vez que ele ficou em segundo lugar em índice de valor de importância, que foi de 32,07, para cana com adubo e 100,49 para cana sem adubo em SPD sobre crotalária (Figura 5A e 5B). Entretanto, a freqüência relativa proporcionou a maior contribuição em termos de IVI para cana com e sem adubo (25 e 25\%), respectivamente, e a dominância relativa $(68,51 \%)$ para cana SPD sobre crotalária sem adubo.

Na região Norte Fluminense, ocorre o predomínio de altas temperaturas e alta luminosidade. As plantas $\mathrm{C}_{4}$ fotossintetizam muito mais eficientemente nestas condições. As plantas $\mathrm{C}_{4}$ se adaptaram nos trópicos, especialmente às altas temperaturas e luminosidade. A tiririca e o capim-massambará são plantas $\mathrm{C}_{4}$, pois possuem um mecanismo de concentração de dióxido de carbono, a enzima PEP carboxilase, que tem alta afinidade pelo $\mathrm{CO}_{2}$, permitindo às plantas reduzirem a abertura estomática e, assim, conservarem água, enquanto fixam o $\mathrm{CO}_{2}$ em velocidade igual ou superior às plantas $\mathrm{C}_{3}$ (TAIZ; ZEIGER, 2004). Dessa maneira, é importante salientar que, deste estudo, conforme pode ser verificado nas Figuras 2, 3, 4, 5 e 6, a Cyperus rotundus e o Sorghum halepense apresentam os maiores IVIs.

$\mathrm{O}$ índice de similaridade entre os tratamentos analisados é considerado alto, com exceção para o cultivo convencional da cana com vegetação espontânea incorporada x cana SPD sobre feijãode-porco, que pode ser considerado baixo (Tabela 2). Esta redução do índice de similaridade nesta última comparação pode estar relacionada com os possíveis efeitos alelopáticos da palhada de feijãode-porco sobre as plantas daninhas.

A similariedade entre as áreas em estudo pode ser explicada pelo fato do sistema de plantio direto de cana estar ainda na fase inicial de implantação, refletindo em pouco volume de palha na superfície do solo. De modo geral, inicialmente o SPD não proporcionou dissimilariedade de ocorrência de espécies em relação ao convencional. Porém, espera-se de médio a longo prazo, que ocorra baixa similariedade na comunidade de plantas daninhas na cultura da cana-de-açúcar cultivada em SPD x PC. 

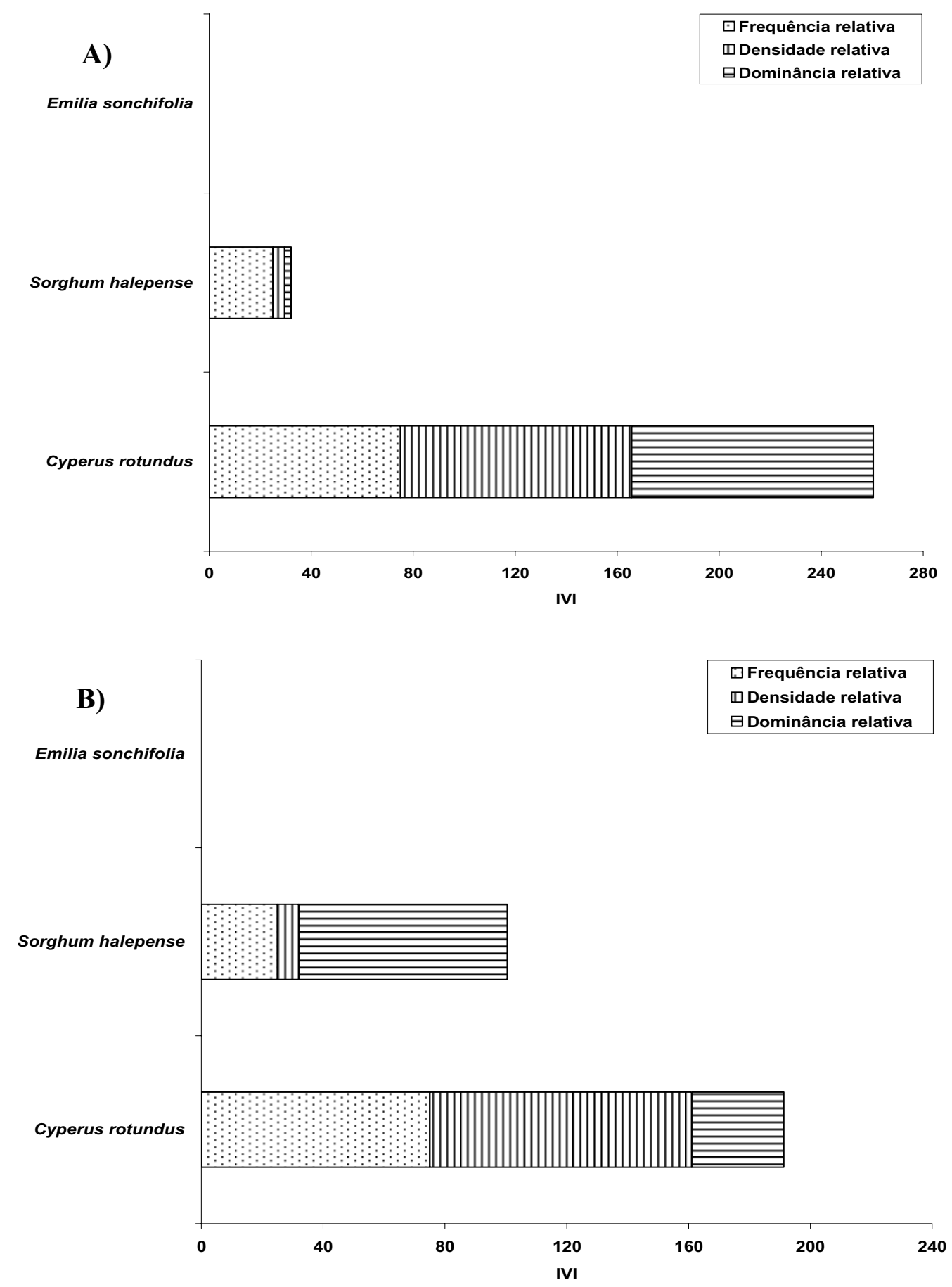

Figura 5. Índice de Valor de Importância (IVI) das principais espécies de plantas daninhas amostradas em área experimental de cana-planta em sistema de plantio direto em Campos dos Goytacazes - RJ, A) cana SPD sobre crotalária juncea com adubo; B) cana SPD sobre crotalária juncea sem adubo 
Tabela 2. Índice de Similaridade na comunidade de plantas daninhas na cultura da cana-de-açúcar em área experimental com plantio direto e convencional na Fazenda Abadia em Campos dos Goytacazes - RJ

\begin{tabular}{|c|c|}
\hline Comparações & Índice de Similaridade (\%) \\
\hline cana-planta adubada x cana-planta não adubada & 85,71 \\
VE cana-planta PC x FP cana-planta PD & 40,00 \\
VE cana-planta PC x MP cana-planta PD & 100,00 \\
VE cana-planta PC x CR cana-planta PD & 80,00 \\
\hline
\end{tabular}

${ }^{1 /} \mathrm{PD}=$ plantio direto, $\mathrm{PC}=$ plantio convencional, $\mathrm{VE}=$ vegetação espontânea, $\mathrm{FP}=$ feijão-de-porco, $\mathrm{MP}=$ mucuna preta e $\mathrm{CR}=$ crotalária juncea.

A dissimilariedade entre áreas foi justificada por Oliveira (2005) pelas diferenças entre solos, manejo do solo e o empregado na condução da lavoura de cana-de-açúcar (adubação, irrigação, controle de pragas e doenças), pelas medidas de controle das plantas daninhas (cultural, mecânico, químico), utilização de herbicidas com diferentes mecanismos de ação que contribuem para selecionar flora diversificada. Entretanto, vale ressaltar que, por ser um ambiente experimental e por ocupar área consideravelmente pequena, isso pode restringir ainda mais a dissimilariedade entre os dois manejos de solo empregados neste trabalho com a cana-deaçúcar.
Nota-se que o menor índice de similaridade foi observado quando se compara a cana PC com VE incorporada com a cana SPD sobre feijão-de-porco $(40,00 \%)$. Este resultado pode ser explicado pelos efeitos diferenciados proporcionados entre os dois métodos de manejo do solo, bem como pelo precoce efeito benéfico do feijão-de-porco no sistema de plantio direto sobre a flora infestante.

Na Tabela 3, é apresentado o resultado do número de plantas e matéria seca de tiririca, a espécie predominante diagnosticada no levantamento fitossociológico da área experimental.

Tabela 3. Número de plantas e matéria seca de tiririca em função das espécies de plantas de cobertura em sistema de plantio direto e convencional da cana-de-açúcar com e sem adubo no plantio, em Campos dos Goytacazes - RJ

\begin{tabular}{ccc}
\hline Plantas de cobertura e sistema de manejo & Número de plantas & Matéria seca \\
\hline & $-----\left(\mathrm{m}^{2}\right)-----$ & $----\left(\mathrm{kg} \mathrm{ha}^{-1}\right)-----$ \\
Crotalária juncea - cana PD & $38 \mathrm{~b}^{1}$ & $107 \mathrm{~b}$ \\
Feijão-de-porco - cana PD & $0 \mathrm{~b}$ & $0 \mathrm{~b}$ \\
Mucuna preta - cana PD & $42 \mathrm{~b}$ & $156 \mathrm{~b}$ \\
Veg. espontânea - cana convencional & $224 \mathrm{a}$ & $636 \mathrm{a}$ \\
\hline Médias & 76 & 225 \\
\hline CV $(\%)$ & 41 & 53 \\
\hline
\end{tabular}

${ }^{1}$ Médias na coluna seguidas por letras minúsculas diferentes são diferentes pelo teste de Tukey em nível de 5\% de probabilidade.

A cana-de-açúcar cultivada em SPD se apresentou com número e fitomassa seca de tiririca (planta daninha predominante) significativamente menor do que a cana PC com vegetação espontânea incorporada, porém, não diferindo entre si signicativamente $(\mathrm{P}<0,05)$ (Tabela 3$)$. Assim, o PC proporcionou acréscimos no número e fitomassa seca de tiririca de 740 e $726 \%$ a mais em relação ao SPD.

Para o número total de folhas estreitas e de plantas daninhas, observaram-se semelhanças com relação ao verificado para espécie predominante (Tabelas 3 e 4). 
Tabela 4. Número total de plantas folhas estreitas (TFE) e total de plantas daninhas (TPD) em função das espécies de plantas de cobertura em sistema de plantio direto e convencional da cana-de-açúcar com e sem adubo no plantio, em Campos dos Goytacazes - RJ

\begin{tabular}{ccc}
\hline \multirow{2}{*}{ Plantas de cobertura e sistema de manejo } & \multicolumn{2}{c}{ Número de plantas } \\
\cline { 2 - 3 } & TFE & TPD \\
\hline Crotalária juncea - cana PD & $-13 \mathrm{~b}$ & $43 \mathrm{~b}$ \\
Feijão-de-porco - cana PD & $21 \mathrm{~b}$ & $22 \mathrm{~b}$ \\
Mucuna preta - cana PD & $43 \mathrm{~b}$ & $43 \mathrm{~b}$ \\
Veg. espontânea - cana convencional & $225 \mathrm{a}$ & $225 \mathrm{a}$ \\
\hline Médias & 83 & 83 \\
\hline CV $(\%)$ & 39 & 40 \\
\hline
\end{tabular}

${ }^{1}$ Médias na coluna seguidas por letras minúsculas diferentes são diferentes pelo teste de Tukey em nível de 5\% de probabilidade.

Portanto, o número total de folhas estreitas e de plantas daninhas totais, respectivamente, foram 531 e $525 \%$ superiores no preparo convencional em comparação ao sistema de plantio direto de cana-deaçúcar. Dessa maneira, possivelmente, a incidência de plantas daninhas no PC certamente causou limitações à produtividade da cana, pois, efetivamente, no PC, a competição por luz (inicialmente), água e nutrientes foi muito maior que no SPD de cana. Isto corrobora o trabalho de Pereira e Velini (2003), os quais verificaram que o sistema de plantio direto apresentou maior eficiência no controle cultural das plantas daninhas que os sistemas de cultivo mínimo e preparo convencional, reduzindo o número total de indivíduos da comunidade infestante.

Severino e Christoffoleti (2001) também observaram que palhada de leguminosas utilizadas de adubo verde reduziram a germinação e produção de fitomassa seca das plantas daninhas. Todavia, outros autores ainda verificaram que espécies de adubos verdes são mais hábeis em reduzir o número de plantas e outras em reduzir a produção de biomassa (ERASMO et al., 2004). Entretanto, não foi possível observar os efeitos indicados por estes últimos autores, uma vez que os resultados obtidos das espécies daninhas da flora estudada não indicaram estas variações de efeitos de crotalária, de feijão-de-porco e de mucuna.

De acordo com os resultados de ATR e produtividade de colmos de cana apresentados no Quadro 5, pode-se observar que a produtividade da cana-de-açúcar conduzida convencionalmente foi $27 \%$ menor que a cana cultivada em sistema de plantio direto.

Dentre outros fatores que influenciaram negativamente para a cana apresentar menor produtividade no $\mathrm{PC}$, destaca-se a maior incidência de plantas daninhas, o que, possivelmente, contribuiu significativamente para esta redução da produção.

Não houve diferença significativa dos tratamentos para açúcares teoricamente recuperáveis (ATR) (Quadro 5). Assim, não foram observados efeitos indiretos da incidência e da dinâmica de plantas daninhas da área experimental sobre esta característica tecnológica da cana-de-açúcar. 
Quadro 5. Resultado de açúcares teoricamente recuperáveis (ATR) e de produtividade da cana-de-açúcar em função da utilização de adubos verdes nos sistemas plantio direto e convencional em Campos dos Goytacazes - RJ

\begin{tabular}{ccc}
\hline Espécie de Cobertura e Sistema de Manejo & ATR & Produtividade \\
\hline & $--\mathrm{kg} \mathrm{ton}^{-1}-$ & $--\mathrm{kg} \mathrm{ha}^{-1}--$ \\
Crotalária juncea - cana PD & $126,8 \mathrm{a}^{1}$ & $131.909 \mathrm{a}$ \\
Feijão-de-porco - cana PD & $130,7 \mathrm{a}$ & $141.278 \mathrm{a}$ \\
Mucuna preta - cana PD & $132,8 \mathrm{a}$ & $134.403 \mathrm{a}$ \\
Veg. espontânea - cana convencional & $130,1 \mathrm{a}$ & $99.008 \mathrm{~b}$ \\
\hline Média & 130,1 & 126.650 \\
\hline CV $(\%)$ & 6 & 8 \\
\hline
\end{tabular}

${ }^{1 /}$ Médias na coluna, seguidas por letras diferentes, são diferentes pelo teste de Tukey em nível de 5\% de probabilidade.

\section{Conclusões}

As espécies Cyperus rotundus e Sorghum halepense apresentaram os maiores índices de valor de importância na área experimental.

O SPD de cana-de-açúcar sobre feijão-de-porco apresentou o menor índice de similariedade na comunidade de plantas daninhas em relação à cana cultivada convencionalmente.

A incidência de plantas daninhas na cana PC foi 531 e $525 \%$ superior à cana SPD e contribuiu para a redução de $27 \%$ na produtividade.

\section{Referências}

AZANIA, A. A. P. M.; AZANIA, C. A. M.; GRAVENA, R.; PAVANI, M. C. M. D.; PITELLI, R. A. Interferência na palha de cana-de-açúcar (Saccharum spp.) na emergência de espécies de plantas daninhas na família convolvulaceae. Revista Planta Daninha, Viçosa, v. 20, n. 2, p. 207-212, 2002.

COELHO, F. C.; FREITAS, S. D. E P.; MONNERAT, P. H.; DORNELLES, M. S. Efeitos sobre a cultura do feijão das adubações com nitrogênio e molibdênio e do manejo de plantas daninhas. Revista Ceres, Viçosa, v. 48, n. 278, p. 455-467, 2001.

COMPANHIA NACIONAL DE ABASTECIMENTO CONAB. Revista Indicadores da Agropecuária, Brasília, v. 9, ano XIV, p.8, 2005.

CURTIS, J. I.; MCINTOSH, R. P. The interrelations of certain analytic and synthetic phytosociological characters. Ecology, Washington, v. 31, n. 3, p. 434-455, 1950.
DEUBER, R. Ciência das plantas infestantes: manejo. 2. ed. Campinas: Degaspari, 1997.

DURIGAN, J. C. Manejo da tiririca (Cyperus rotundus L.) antes e durante a implantação da cultura de cana-deaçúcar (Saccharum spp.). 1991. Tese (Livre-Docência) Universidade Estadual de São Paulo, Jaboticabal, 1991.

DURIGAN, J. C.; MARTINI, G.; LEITE, G. J. Controle químico da tiririca (Cyperus rotundus L.) com e sem cobertura do solo com a palha remanescente da colheita mecânica da cana-de-açúcar. In: CONGRESSO NACIONAL DA STAB, 8., 2002, Recife. Anais...Recife: STAB, 2002. p. 150-157.

ERASMO, E. A. L.; AZEVEDO, W. R.; SARMENTO, R. A.; CUNHA, A. M.; GARCIA, S. L. R. Potencial de espécies utilizadas como adubo verde no manejo integrado de plantas daninhas. Revista Planta Daninha, Viçosa, v. 22, n. 3, p. 337-342, 2004.

EVANGELISTA JUNIOR, A. C.; PAVANI, M. C. M. D.; ALVES, P. L. C. A.; CORÁ, J. E.; GODOY, G. P.; PATTI, G. P. Influência de diferentes coberturas mortas na comunidade infestante em área de plantio direto. Revista Planta Daninha, Viçosa, v. 10, (suplemento), p. 23, 2004.

FERREIRA, F. A.; FERREIRA, L. R.; SILVA, A. A.; GOMES, J. M. Manejo integrado de plantas daninhas em hortaliças. In: ZAMBOLIM, L. (Ed.). Manejo integrado de doenças, pragas e plantas daninhas. Viçosa: UFV, 2000. p. 365-372.

FERREIRA, P. V. Estatística Experimental Aplicada à Agronomia. 3. ed. Maceió: EDUFAL, 2000.

FIGUEIREDO, P. A. M.; BARBOSA, M. H. P.; ANDRADE, L. A. B.; ANJOS, I. A.; QUINTELA, A. C. R. Controle de plantas daninhas e rendimentos de colmos e ATR da variedade SP80-1842, pelo palhiço, vinhaça e herbicidas em áreas de colheita mecanizada de cana crua. 
In: CONGRESSO NACIONAL DA STAB, 8., 2002, Recife. Anais... Recife: STAB, 2002. p. 201-207.

FREITAS, S. P.; COELHO, F. C.; PESSANHA, H. M. Manejo de plantas daninhas na cultura da cana-de-açúcar na região Norte Fluminense. Boletim técnico UENF, v. 1, n. 2, 2001.

JAKELAITIS, A.; FERREIRA, L. R.; SILVA, A. A.; AGNES, E. L.; MIRANDA, G. V.; MACHADO, A. F. L. Dinâmica populacional de plantas daninhas sob diferentes sistemas de manejo nas culturas de milho e feijão. Revista Planta Daninha, Viçosa, v. 21, n. 1, p. 7179, 2003.

KISSMANN, K. G. Plantas infestantes e nocivas. 2. ed. São Paulo: BASF, 1997.

LACERDA, A. L. S.; VICTORIA FILHO, R. Dinâmica populacional de plantas daninhas em dois sistemas de manejo do solo. Revista Planta Daninha, Viçosa, v. 10, (Suplemento), p. 235, 2004.

LORENZI, H. Plantas daninhas do Brasil: terrestres, aquáticas, parasitas e tóxicas. 3. ed. Nova Odessa: Instituto Plantarum, 2000.

MEDEIROS, A. R. M. Determinação de potencialidades alelopáticas em agroecossistemas. 1989. Tese (Doutorado em Fitotecnia) - Escola Superior de Agricultura "Luiz de Queiroz", Piracicaba, 1989.

MUELLER-DOMBOIS, D.; ELLENBERG, H. A. Aims and methods of vegetation ecology. New York: John Wiley, 1974.

OLIVEIRA, A. R. Levantamento fitossociológico e controle de capim-camalote (Rottboellia exaltata L.) na cultura da cana-de-açúcar. 2005. Tese (Doutorado em Produção Vegetal) - Universidade Estadual do Norte Fluminense Darcy Ribeiro, Campos dos Goytacazes, 2005.
PEREIRA, F. A. R.; VELINI, E. D. Sistemas de cultivo no cerrado e dinâmica de populações de plantas daninhas. Revista Planta Daninha, Viçosa, v. 21, n. 3, p. 355-363, 2003.

PITELLI, R. A. Interferência das plantas daninhas em culturas agrícolas. Informe Agropecuário, Brasília, v. 11, n. 129 , p. 16-27, 1985.

PITELLI, R.A.Estudos fitossociológicos em comunidades infestantes de agroecossistemas. Journal ConsHerb, São Paulo, v. 1, n. 2, p. 1-7, 2000.

RAIJ, B. V.; CANTARELLA, H.; QUAGGIO, J. A.; FURLANI, A. M. C. Boletim 100: Recomendações de adubação e calagem para o Estado de São Paulo. 2. ed. Instituto Agronômico: Campinas, 1996. 285 p.

RIBEIRO JÚNIOR, J. I. Análises Estatísticas no SAEG. Viçosa: UFV, 2001.

SÁ, J. C. M. Reciclagem de nutrientes dos resíduos culturais, e estratégia de fertilização para produção de grãos no sistema de plantio direto. In: SEMINÁRIO SOBRE O SISTEMA DE PLANTIO DIRETO NA UFV, 1., 1998, Viçosa. Anais... Viçosa: Universidade Federal de Viçosa, 1998. p. 19-61.

SEVERINO, F. J.; CHRISTOFFOLETI, P. J. Efeitos de quantidades de fitomassa de adubos verdes na supressão de plantas daninhas. Revista Planta Daninha, Viçosa, v. 19, n. 2, p. 223-228, 2001.

SORENSEN, T. A method of stablishing groups of equal amplitude in plant society of species content. In: ODUM, E. P. (Ed.). Ecology. 3.ed. México: Iteramericana, 1972.

TAIZ, L.; ZEIGER, E. Fisiologia Vegetal. 3. ed. Porto Alegre: Artmed, 2004.

VICTÓRIA FILHO, R. Estratégias de manejo de plantas daninhas. In: ZAMBOLIM, L.; CONCEIÇÃO, M. Z.; SANTIAGO, T. (Ed.). O que Engenheiros Agrônomos devem saber para orientar o uso de produtos fitossanitários. Viçosa: Suprema. 2003. cap.8, p. 317375. 
